\title{
Development and research of metal-cladding additive to lubricants
}

\author{
Victor Balabanov* \\ Russian State Agrarian University- Moscow Timiryazev Agricultural Academy, 127550 Moscow \\ Timiryazevskaya 49, Russia
}

\begin{abstract}
The article indicates that one of the directions of increasing the wear resistance of rubbing parts of machines and equipment, reducing friction losses and temperatures in the friction zone is the use of special metal-plating additives to lubricants. The Engineering Center of the Timiryazev Academy has developed an experimental metal-cladding additive under the code name "MP-21" based on a mixture of fatty acids (oleic, stearic, linoleic) and plastic metal salts of the same fatty acids. The tribotechnical properties of lubricating compositions with various additives in recommended concentrations were investigated on a modernized Timken-mashine friction machine in a steady state using samples from real rolling bearing assemblies. It has been established that the developed metal-cladding additive "MP-21", along with the additive Renom Engine, provides maximum antiwear properties and allows to reduce the wear of rubbing samples in comparison with other investigated additives from $30 \%$ to several.
\end{abstract}

\section{Introduction}

The current stage of Russia's economic development is characterized by the growth of domestic and imported automotive and agricultural equipment with high mileage and service life. The operation of such equipment leads to a significant increase in the cost of its maintenance: an increase in the consumption of fuel and lubricants and spare parts, an increase in the volume of repair and adjustment work, etc. [1-2].

One of the directions of increasing the wear resistance of rubbing parts of machines and equipment, reducing friction losses and temperatures in the friction zone is the use of special metal-plating additives to lubricants [1-2].

At present, many such additives are known that implement metal-coating of rubbing surfaces during operation and implement the effect of selective transfer during friction. They contain a mixture of fatty acids, salts or powders of plastic metals, glycerin and a number of other components [1-10].

Numerous studies note that the process of cladding rubbing joints with ductile metals is carried out as a result of recovery and deposition of ductile metals from salts in the presence of surfactants contained in the lubricant composition. When used in a lubricant

\footnotetext{
* Corresponding author: vbalabanov@,rgau-msha.ru
} 
composition, a composite protective film of plastic additives with high antiwear and antifriction properties is formed on the friction surfaces [1-10].

In this regard, the development and research of such additives is a modern and urgent task for increasing the durability of various types of machinery and equipment.

\section{Materials and methods}

The Engineering Center of the Timiryazev Academy (ECTA) has developed an experimental metal-cladding additive under the code name "MP-21" based on a mixture of fatty acids (oleic, stearic, linoleic) and plastic metal salts of the same fatty acids.

The tribotechnical properties of lubricating compositions with various additives in recommended concentrations were studied at the Russian State Agrarian University Moscow Timiryazev Agricultural Academy (RSAU-MTAA) on a modernized friction machine of the Timken-mashine brand in a steady state using samples from real rolling bearing assemblies: an inner race and rollers with a diameter of $8 \mathrm{~mm}$, rolling bearing type 7202 , made of ball bearing steel.

The design of the modernized Timken-Mashine friction machine is shown in Figure 1, and a general view in Figure 2.

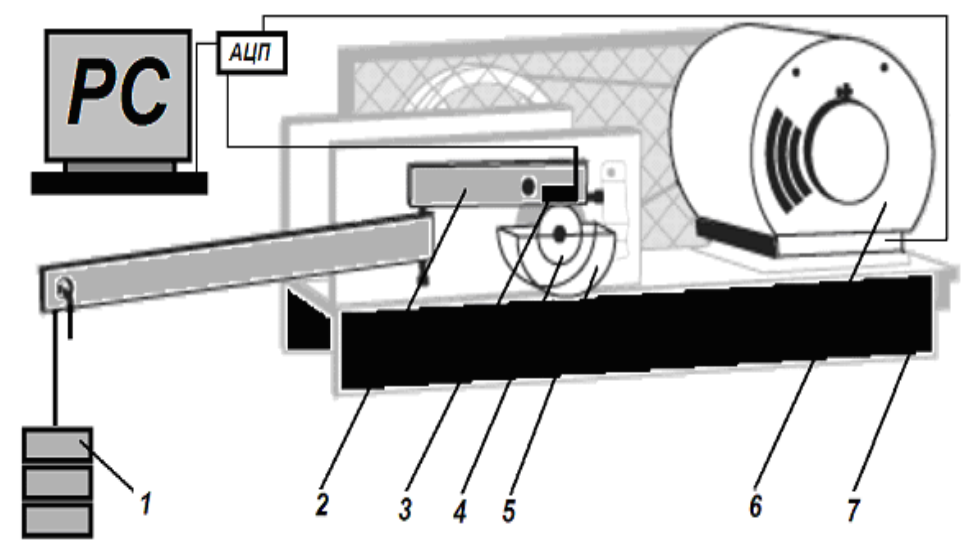

Fig. 1. Scheme of the modernized Timken-Mashine: 1 - cargo; 2 - load mechanism; 3 - upper roller sample with a temperature sensor; 4 - lower annular sample; 5 - a cuvette for lubricant; 6 - electric motor; 7 - bed; ADC - analog-to-digital converter; PC - personal computer with software

The laboratory tribotechnical tests were determined by the structural capabilities of the friction machine: specific pressure in the contact zone $\mathrm{p}=5 \mathrm{MPa}$, sliding speed $\mathrm{v}=1.83$ $\mathrm{m} / \mathrm{s}$, lubricant was supplied to the friction zone by spreading, the time of one test was $\mathrm{t}=$ $3600 \mathrm{~s}$. 


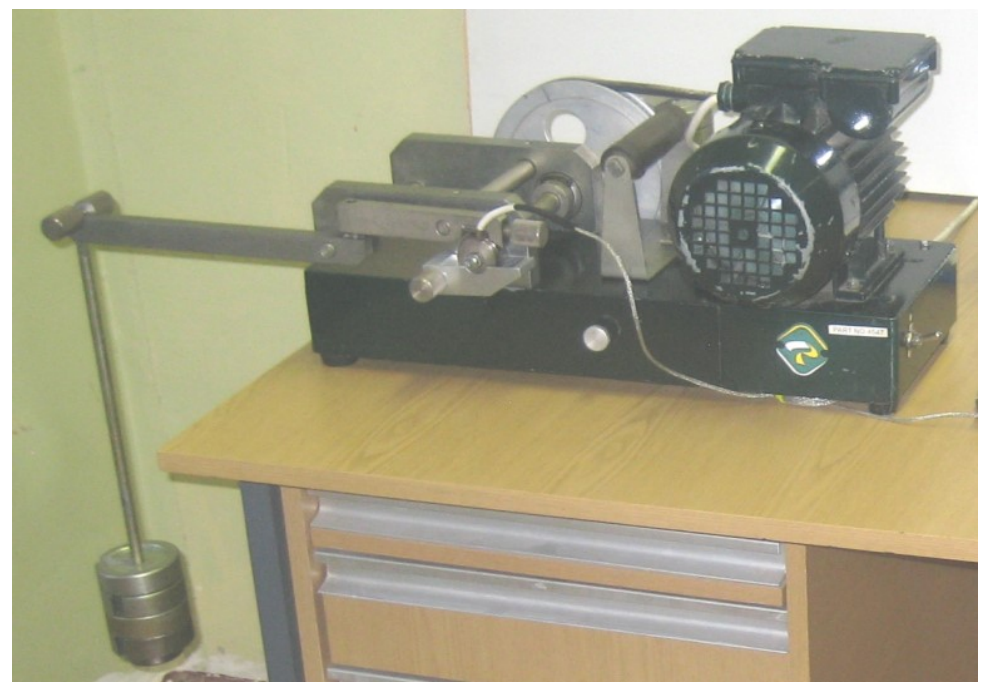

Fig. 2. General view of the modernized Timken-Machine

The principle of operation of the Timken-Mashine installation is based on the implementation of a rotary motion according to the "ring-roller" scheme with the friction of the upper roller sample 3 against the lower annular sample 4 (Figures 3-4).

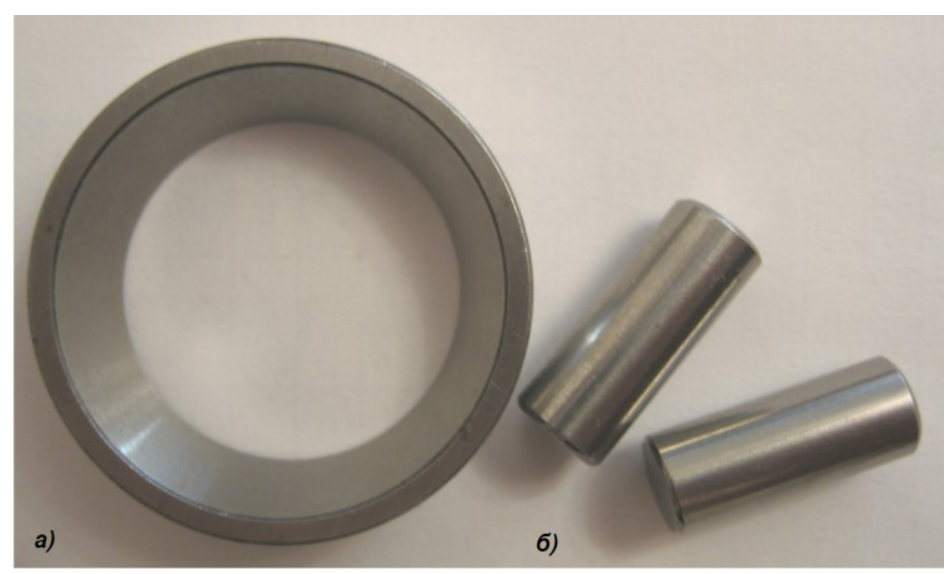

Fig. 3. General view of the samples for tribological testing on a Timken-Mashine: a - lower annular, b - upper roller

a)
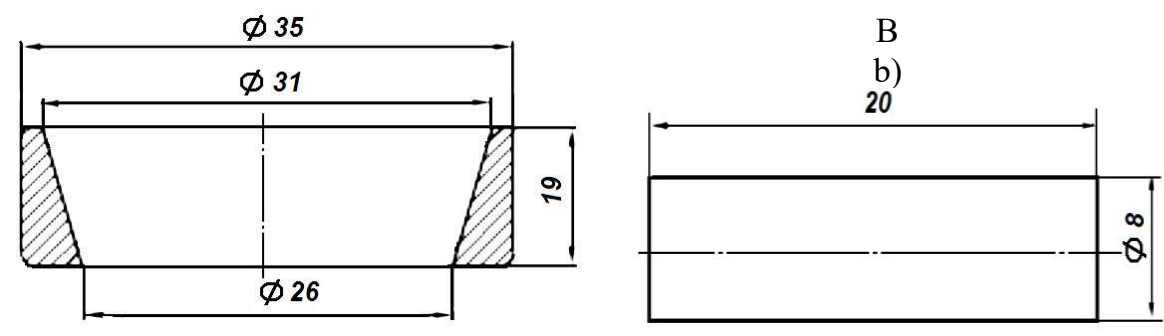

Fig. 4. Sketches of samples for the Timken-Mashine: a - lower annular, b - upper roller 
The composition of the studied lubricating compositions is presented in the table 1 .

Table 1. The composition of the studied lubricating compositions [1-10]

\begin{tabular}{|l|c|c|c|}
\hline \multicolumn{1}{|c|}{ Name } & Manufacturer & Type of additive & Content, $\%$ \\
\hline Resurs & Firm «VMPAauto» & Metal-clad & 5,0 \\
\hline Motor Healer & JSC «Fine Metal Powders» & Metal-clad & 5,0 \\
\hline MP-21 & ECTA & Metal-clad & 5,0 \\
\hline Valena & Kuskovo grease plant & Metal-clad & 0,6 \\
\hline MKF-18NT & Firm «Tribotechnology» & Metal-clad & 5,0 \\
\hline Kremnezem & GOSNITI & Geomodifier & 1,0 \\
\hline Bemit & GOSNITI & Geomodifier & 1,0 \\
\hline DLCf & Firm «Tribotechnology» & Geomodifier & 1,0 \\
\hline Renom Engine & Firm «Autohimproject» & Metal-clad & 5,0 \\
\hline
\end{tabular}

The results of tests of the same structural materials on pure Lukoil-Super 10W40 oil without additives were taken as a comparison base.

\section{Results and discussion}

The results of laboratory tribotechnical wear tests are presented in Figure 5.

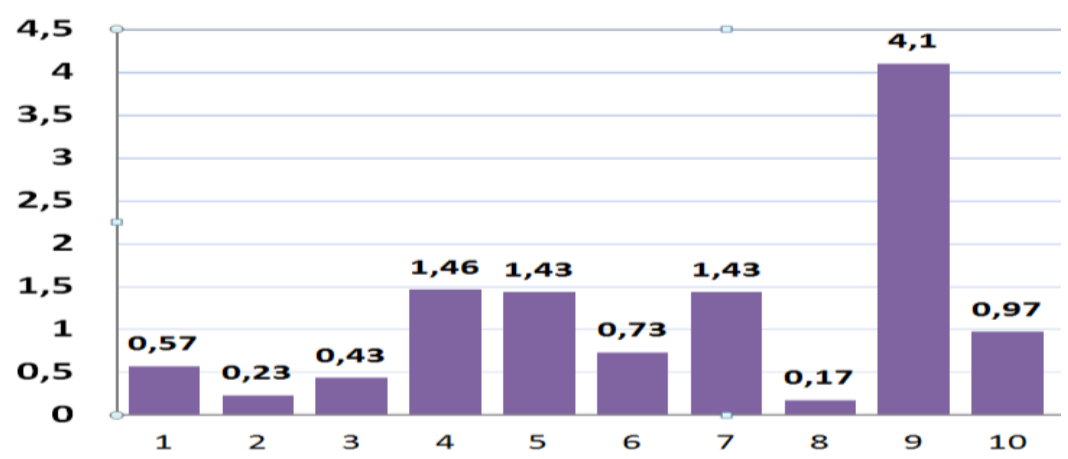

Fig. 5. Wear of samples (I, mg) during tribotechnical tests of various lubricating compositions: 1 Resurs; 2 - Motor Healer; 3 - «MP-21»; 4 - Lukoil-Super 10W40 (base); 5 - Valena; 6 Kremnezem; 7 - Bemit; 8 - Renom Engine; 9 - DLCf; 10 - MKF-18NT

The wear recovery of the test samples was determined at the end of each test by the weighing method on an WA-21 analytical balance (Mechaniki zaklady precyzyjnej, Poland) with a weighing accuracy of up to $0.0001 \mathrm{~g}$.

Metal-cladding additive to lubricants contributes to the filling of microdefects (scuffs) on the crankshaft journals with plastic metals with subsequent implementation during operation in rubbing joints of selective transfer during friction (wear-free effect).

\section{Conclusions}

1. The test result indicates that the use of the additive ensures the formation of a protective composite film of plastic metals contained in the additive on the rubbing surfaces, which reduces the wear rate of steel samples by 8.5 times.

2. It has been established that the developed metal-cladding additive "MP-21", along with the additive Renom Engine, provides maximum antiwear properties and allows to 
reduce the wear of rubbing samples in comparison with other investigated additives from $30 \%$ to several times.

\section{Acknowledgments}

The article was prepared with the support of the Ministry of Education and Science of Russia within the framework of agreement No. 075-15-2021-032 dated March 23, 2021 on the provision of a grant in the form of a subsidy for the creation and development of an engineering center on the basis of an educational institution of higher education and (or) a scientific organization in within the framework of the federal project "Development of infrastructure for research and training" of the national project "Science and Universities".

\section{References}

1. D.N. Garkunov, Wear and tear, 616 (2001)

2. D.N. Garkunov, V.I. Balabanov, Heavy mechanical engineering, 2, 18 (2000)

3. V.I. Balabanov, G.K. Potapov, Diagnostics, reliability and repair of machines: Collection of scientific works of MGAU, 92 (1995)

4. V.I. Balabanov, Vestnik mashinostroeniya, 8, 14 (2001)

5. V.I. Beklemyshev, I.I. Makhonin, A.F. Letov, Herald of mechanical engineering, 10, 51 (2004)

6. V.I. Balabanov, V.I. Beklemyshev, I.I. Makhonin, V.K. Filippov, Rural machine operator, 11, 40 (2005)

7. A.F. Sinelnikov, V.I. Balabanov, Automotive oils, fuels and technical fluids, 155 (2007)

8. V.I. Balabanov, Nanotechnology and nanopreparations for automotive machinery, 77 (2008)

9. V.F. Fedorenko, M.N. Erokhin, Nanotechnology and nanomaterials in the agricultural sector, 312 (2011)

10. V.I. Balabanov, V.Yu. Bolgov, Car additives and inclusions, 224 (2011) 